\title{
Eranina Monné (Coleoptera, Cerambycidae, Lamiinae) e novo gênero de Hemilophini
}

\author{
Maria Helena M. Galileo ${ }^{1,3}$ \& Ubirajara R. Martins s.3 $^{2,3}$
}

\begin{abstract}
${ }^{1}$ Museu de Ciências Naturais, Fundação Zoobotânica do Rio Grande do Sul. Caixa Postal 1188, 90001-970 Porto Alegre, RS, Brasil. ${ }^{2}$ Museu de Zoologia, Universidade de São Paulo. Caixa Postal 42494, 04218-970 São Paulo, SP, Brasil.

${ }^{3}$ Pesquisador do $\mathrm{CNPq}$
\end{abstract}

\begin{abstract}
Eranina Monné (Coleoptera, Cerambycidae, Lamiinae) and a new genus of Hemilophini. New species described in Eranina: E. moysesi and E. esquinas from Costa Rica; E. rondonia from Brazil (Rondônia) and E. hovorei from Ecuador. A key to the 34 species of Eranina is added. The monotypic genus Eraninella gen. nov. is erected for Eranina longiscapus (Bates, 1881).
\end{abstract}

KEYWORDS. Eraninella; key; Neotropical; new taxa; taxonomy.

RESUMO. Eranina Monné (Coleoptera, Cerambycidae, Lamiinae) e novo gênero de Hemilophini. Novas espécies descritas em Eranina Monné, 2005: E. moysesi e E. esquinas da Costa Rica; E. rondonia do Brasil (Rondônia) e E. hovorei do Equador. Acrescenta-se chave para as 34 espécies de Eranina. O gênero monotípico Eraninella gen. nov. é criado para Eranina longiscapus (Bates, 1881).

PALAVRAS-CHAVE. Eraninella; chave; Neotropical; novos táxons; taxonomia.

Monné (2005) constatou que o gênero Erana Bates, 1866, estava preocupado por gênero de Aves proposto por Gray em 1840 e deu-lhe o novo nome, Eranina. Bates (1866) estabeleceu Erana para única espécie amazônica, E. cincticornis Bates, 1866.

Bates (1874) acrescentou ao gênero uma segunda espécie, E. pusilla da Nicarágua. Ao cuidar das espécies de Erana na "Biologia Centrali Americana", Bates (1879-1885), ampliou bastante o número de espécies, quando incluiu outras nove.

Bates (1881) ainda publicou a descrição de Tyrinthia longiscapus do Brasil (Rio de Janeiro) aqui considerada a espécie-tipo do gênero Eraninella gen. nov. descrito adiante.

Bruch (1911) e Fisher (1938) descreveram uma espécie cada um, respectivamente, da Argentina (Tucumán) e do Brasil (Santa Catarina).

Martins \& Galileo (1989) reviram as espécies sul-americanas de Erana quando descreveram quatro espécies, todas do Brasil e forneceram chave para identificação. Após essa contribuição, Galileo \& Martins $(1998,1999,2004,2005,2007)$ e Martins \& Galileo (1993), publicaram em diversos artigos, outras 14 espécies. Conheciam-se, então, 31 espécies em Eranina e ora acrescentam-se mais quatro e transfere-se uma. Para melhor diagnosticar as 34 espécies de Eranina, apresenta-se uma chave modificada de Martins \& Galileo (1989).

O material contido neste artigo foi remetido para estudo por Frank T. Hovore, desafortunadamente falecido recentemente, e envolve espécimes do Instituto Nacional de Biodiversidad, Santo Domingo, Heredia, Costa Rica (INBIO) e do National Museum of Natural History, Washington (USNM). Material adicional nos foi enviado por Larry G. Bezark, Sacramento e pertence à Utah State University, Logan (USUL).
Também está citado no texto material retido para o Museu de Zoologia, Universidade de São Paulo, São Paulo (MZSP).

\section{Eranina moysesi sp. nov.}

(Fig. 1)

Etimologia. O nome específico é uma homenagem a Eleandro Moysés (Museu de Ciências Naturais, Fundação Zoobotânica do Rio Grande do Sul, MCNZ) que muito nos tem auxiliado com ilustrações.

Cabeça amarelo-alaranjada; vértice preto, menos na faixa central. Pubescência branco-amarelada, compacta ou não, atrás dos olhos. Escapo preto com mancha alaranjada no lado interno do ápice. Pedicelo preto. Antenômero III amarelado com anel apical preto; antenômero IV preto; $\mathrm{V}$ branco-amarelado ou com a base enegrecida; VI e VII branco-amarelados; VIII-XI pretos.

Pronoto preto numa faixa central mais alargada na base; amarelado nos lados com pubescência esbranquiçada, densa. Lados do protórax com pubescência compacta branca. Prosterno e mesosterno alaranjados. Mesepimeros, mesepisternos e metepisternos cobertos por densa pubescência branca. Metasterno alaranjado no centro e escurecido ou não nos lados, com pubescência acinzentada e esparsa. Escutelo preto.

Élitros pretos com pequena mancha branco-amarelada que envolve os ápices; pubescência fina, acinzentada. Ápices elitrais arredondados.

Fêmures amarelados. Tíbias pretas. Tarsômeros I e II, pretos; III a V, alaranjados. 
Urosternitos alaranjados com pubescência branca, compacta, nos lados.

Dimensões em mm, holótipo macho/fêmea. Comprimento total 4,9/5,2; comprimento do protórax, $0,9 / 1,0 ;$ maior largura do protórax, 1,2/1,2; comprimento dos élitros, 3,6/3,7; largura umeral, 1,5/1,6.

Material tipo. Holótipo macho, COSTA RICA, Puntarenas: Sirena (Acosa, 1-100 m), 5-24.IV.1995, B. Gamboa col. (INBIO, L N 270500_507900\#4738).

Material adicional. COSTA RICA, Puntarenas: Esquinas (Pen. de Osa, 200 m), fêmea (mau estado de conservação), VIII.1993, M. Segura col. (INBIO, L S 30140_542200\#2314, retido para o MZSP).

\section{Eranina rondonia sp. nov.}

(Fig. 2)

Etimologia. O epíteto é alusivo ao Estado de Rondônia, Brasil.

Cabeça preta, exceto genas alaranjadas. Escapo e pedicelo alaranjados. Antenômero III castanho-alaranjado revestido por pêlos pretos. Antenômero IV, na metade basal, castanhoalaranjado revestido por pêlos pretos e, na metade apical, branco. Antenômero V branco; VI preto com o extremo basal branco; VII-XI pretos.

Protórax alaranjado revestido por fina pilosidade esbranquiçada. Escutelo alaranjado.

Élitros pretos com epipleuras, da base ao meio, e friso sutural, amarelados; pubescência esbranquiçada, mais evidente no quarto apical. Extremidades arredondadas.

Pernas e face ventral do corpo, alaranjadas.

Dimensões em mm, holótipo macho/parátipo fêmea. Comprimento total, 7,7/6,5; comprimento do protórax, 1,4/1,2; maior largura do protórax, 1,9/1,6; comprimento dos élitros, 5,2/4,6; largura umeral, 2,5/2,2.

Material-tipo. Holótipo macho, BRASIL, Rondônia: Ariquemes (22 km SE), 5-16.XI.1996, W. J. Hanson col. (MZSP, doação de F. H. Hovore); parátipo fêmea, mesmos dados do holótipo (USUL).

\section{Eranina esquinas sp. nov.} (Fig. 3)

Etimologia. O nome específico corresponde à localidadetipo, Esquinas, Puntarenas, Costa Rica.

Cabeça alaranjada exceto pequena mancha atrás dos olhos, preta. Escapo preto com mancha avermelhada na metade apical do lado interno. Pedicelo preto. Antenômeros III a VII alaranjados com o VI e o VII mais esbranquiçados; antenômero VIII com a metade basal esbranquiçada e a apical, preta; IX-XI pretos.

Pronoto preto. Partes laterais do protórax alaranjadas com pubescência esbranquiçada. Escutelo preto.

Élitros pretos a acastanhados revestidos por pubescência acinzentada. Extremidades elitrais arredondadas.

Face ventral alaranjada. Mesepimeros, mesepisternos, metepisternos revestidos por pubescência branca. Fêmures alaranjados. Tíbias pretas. Tarsômeros I e II acastanhados; III-V alaranjados.
Dimensões em mm, holótipo macho. Comprimento total 6,2; comprimento do protórax, 1,0; maior largura do protórax, 1,4; comprimento dos élitros, 4,5; largura umeral, 2,0.

Material tipo. Holótipo macho, COSTA RICA, Puntarenas: Esquinas (Bosque, Península de Osa, 200m), VI.1994, M. Segura col. (INBIO L N 302450_545100\#3007).

\section{Eranina hovorei sp nov.}

(Fig. 4)

Etimologia. O epíteto é uma homenagem póstuma a Henry F. Hovore.

Macho. Cabeça com tegumento acastanhado; fronte e genas cobertas por pubescência amarelada, densa e compacta. Antenas castanho-alaranjadas, exceto anel apical acastanhado nos antenômeros II-VII e em toda a extensão dos antenômeros VIII-XI. Franja esparsa de pêlos na margem interna dos antenômeros I a VII.

Protórax acastanhado. Pronoto revestido por pubescência amarelada, exceto estreita faixa junto à margem anterior e área central junto à margem posterior.

Élitros com tegumento acastanhado; pubescência amarelada, compacta, reveste: faixa transversal, próximo do meio que vai da sutura até a declividade lateral; faixa que ocupa os ápices. Extremidades elitrais arredondadas.

Face ventral acastanhada com áreas de pubescência amarelada, compacta, nos lados do prosterno, mesepisternos, mesepimeros, metepisternos, lados do metasterno e lados dos urosternitos I-IV. Pernas castanho-alaranjadas. Fêmures lineares.

Dimensões em mm, holótipo e parátipo machos. Comprimento total, 5,8-6,3; comprimento do protórax, 1,0-1,1; maior largura do protórax, 1,5-1,5; comprimento dos élitros, 4,1-4,4; largura umeral, 1,9-1,9.

Material-tipo. Holótipo macho, EQUADOR, Napo: (Reserva Ethnica Waorani, $1 \mathrm{~km} \mathrm{~S}$, Onkone Gare Camp, Trans. Ent., 00³9’10" S $\left.76^{\circ} 26^{\prime} \mathrm{W}, 220 \mathrm{~m}\right), 4 . I I .1996, \mathrm{~T}$. L. Erwin et al. col., "insecticidal fogging of mostly bare green leaves, some with covering of lichenous or bryophytic plants in terre firm forest. At Trans. 1, Sta. 4, Project MAXUS Lot 1404" (USNM). Parátipo macho (pubescência mal conservada), EQUADOR, "Coca", III.1982, sem nome de coletor (MZSP, doação de K. E. Huedepohl).

Chave para as espécies de Eranina

1. Antenas sem artículos brancos, os flagelômeros acastanhados ou amarelados com ápices acastanhados em pequena extensão .......................... 2

Antenas com alguns artículos inteiramente brancos, às vezes único artículo com anel apical acastanhado a preto

2(1). Protórax unicolor 3

Protórax bicolor 7

3(2). Élitros inteiramente amarelo-alaranjados. (Martins \& Galileo, 1989:82, fig.6) Brasil (Pará, Mato Grosso) 
E. pallidula (Martins \& Galileo, 1989)

Élitros com outros padrões de coloração 4

4(3). Élitros amarelo-alaranjados, exceto úmeros e quarto apical pretos a castanho-avermelhados. (Martins \& Galileo, 1993:171, fig. 2). Colômbia .

E. tauaira (Martins \& Galileo, 1993)

Élitros inteiramente pretos ou com os úmeros alaranjados

5(4). Protórax e escutelo pretos a castanho-escuros; antenômeros X e XI pretos. Guatemala

E. fuliginella (Bates, 1885)

Protórax e escutelo alaranjados a amarelados; antenômeros VII a XI pretos

6(5). Élitros com úmeros alaranjados e grande área dorsal preto-alaranjada pouco contrastante; antenômero III preto com a base amarelada; cabeça alaranjada com as regiões pós-oculares pretas. (Martins \& Galileo, 1993:171, fig. 4). Guiana Francesa, Brasil (Amazonas)

E. cendira (Bates, 1866)

Élitros inteiramente pretos; antenômero III amarelado com o ápice preto; cabeça preta. (Galileo \& Martins, 2005: 67, fig. 5). Honduras

E. flaviventris (Galileo \& Martins, 2005)

7(2). Vértice e área triangular junto à borda anterior do pronoto com pêlos sedosos, esbranquiçados e longos. (Martins \& Galileo, 1989:82, fig.7). Brasil (Santa Catarina) E. ciliata (Fisher, 1938)

Vértice e borda anterior do protórax sem esses pêlos 8

8(7). Pronoto revestido por pubescência branca, compacta, em grande parte da superfície, por exemplo Fig. 4

Pronoto sem grandes áreas de pubescência branca compacta, quando muito com faixas de pubescência

9(8). Élitros com espículo no ângulo marginal. Nicarágua ao Panamá E. leuconoe (Bates, 1881)

Élitros com os ápices arredondados .. 10

10(9). Pubescência do protórax interrompida longitudinalmente por área acastanhada central que se estende do ápice ao quarto basal; grande parte dos élitros cobertos por pubescência branca, compacta. (Galileo \& Martins, 1999:114, fig. 2). Colômbia

E. icambi (Galileo \& Martins, 1999)

Pronoto com duas áreas acastanhadas, estreitas, transversais, uma junto à orla anterior e outra no centro da base; élitros com faixa branco-amarelada, transversal, no meio. Fig. 4. Equador ...

E. hovorei sp. nov.

11(8). Élitros bicolores, isto é, com tegumento amarelado e preto 12

Élitros inteiramente pretos a acastanhados .............. 14

12(11). Urosternitos parcialmente amarelados. México, Guatemala .... E. pectoralis (Bates, 1881)

Urosternitos pretos 13

13(12). Pronoto amarelado a alaranjado com faixa acastanhada restrita a cada lado do protórax; élitros com espículo no ângulo marginal. Fig. 5. Guatemala ao Panamá E. fulveola (Bates, 1881)

Pronoto amarelado a alaranjado com faixas largas, laterais, de tegumento acastanhado; élitros sem espículo no ângulo marginal. (Martins \& Galileo, 1989:82, fig. 5). Paraguai, Argentina

E. argentina (Bruch, 1911)

14(11). Protórax em grande parte amarelado. (Martins \& Galileo, 1989:83, fig. 9). Brasil (Goiás)

E. diana (Martins \& Galileo, 1989)

Protórax em grande parte preto 15

15(14). Centro do pronoto sem faixa longitudinal de pubescência amarelo-esbranquiçada ................. 16

Centro do pronoto com faixa longitudinal de pubescência amarelo-esbranquiçada 17

16(15). Flagelômeros pretos; faixas longitudinais amareloesbranquiçadas do pronoto bem largas; fêmures pretos; metafêmures dos machos com projeção triangular no lado inferior. (Martins \& Galileo, 1989: 83, figs. 3, 8). Brasil (São Paulo ao Rio Grande do Sul) .................. E. meyeri (Martins \& Galileo, 1989)

A maioria dos flagelômeros alaranjados; lados do pronoto com faixa de pubescência amareloesbranquiçada estreita ou não; fêmures alaranjados, às vezes, com pequena área apical preta; metafêmures dos machos sem projeção no lado inferior. México a Costa Rica .E. pusilla (Bates, 1874)

17(15). Faixa de pubescência amarelo-esbranquiçada restrita ao meio do pronoto. México.

E. univittata (Bates, 1881)

Faixas de pubescência amarelo-esbranquiçada no meio e nos lados do pronoto 18

18(17). Faixa de pubescência amarelo-esbranquiçada do centro do pronoto expandida para os lados no nível do meio e conectada à mancha látero-anterior. Guatemala E. florula (Bates, 1881)

Faixa de pubescência amarelo-esbranquiçada do centro do pronoto não conectada com as faixas laterais . 19

19(18). Vértice com fina pubescência cinérea; protórax estreitado no terço anterior. México ao Panamá 
E. dispar (Bates, 1881)

Vértice com faixa de pubescência amarelada; protórax não estreitado no terço anterior. Fig. 7. Guatemala E. suavissima (Bates, 1881)

20(1). Pronoto unicolor 21

Pronoto bicolor

21(20). Élitros pretos, cada um com três faixas transversais amareladas: uma na base, uma adiante do meio e uma na extremidade. (Galileo \& Martins, 1999:115, fig. 3). Colômbia . E. curuca (Galileo \& Martins, 1999)

Élitros inteiramente pretos ou com friso sutural amarelado .22

22(21). Cabeça alaranjada; antenômeros IV a VII brancos; pronoto preto (alaranjado só nos lados do protórax); escutelo preto; élitros com friso sutural não contrastante. (Galileo \& Martins, 2005: 67, fig. 4). Costa Rica

E. costaricensis (Galileo \& Martins, 2005)

Cabeça preta a acastanhada; metade apical do antenômero IV, inteiramente no V e base do VI, brancos; pronoto e escutelo alaranjados; friso sutural dos élitros com pubescência amarelada e contrastante. (Fig. 2). Brasil (Rondônia)

E. rondonia sp. nov.

23(20). Vértice e área junto à borda anterior do protórax alaranjados com pubescência esbranquiçada, sedosa, longa. Brasil (Amapá) E. nigrita (Galileo \& Martins, 1991)

Vértice e pronoto sem essa pubescência 24

24(23). Regiões ântero-laterais do pronoto revestidas por pubescência rósea. (Galileo \& Martins, 2004: 251, fig. 4). Panamá ..... E. rosea (Galileo \& Martins, 2004) Pubescência do pronoto com outro colorido ............ 25

25(24). Élitros bicolores ............................................................. 26

Élitros pretos .28

26(25). Lados do pronoto com faixa de pubescência esbranquiçada. (Martins \& Galileo, 1993:171, fig.1). Venezuela, Colômbia

E. piriana (Martins \& Galileo, 1993)

Lados do pronoto sem faixa de pubescência branca .27

27(26). Apenas o antenômero IV, exceto o ápice, esbranquiçado; área alaranjada do meio do pronoto, triangular e não atinge a base; élitros com mancha circum-escutelar preta; limite entre as partes amarelada e preta dos élitros, irregular e transversal. (Galileo \& Martins, 1998:253, fig. 6). Brasil (Santa Catarina) ... E. porongaba (Galileo \& Martins, 1998) Antenômeros IV, V e base do VI esbranquiçados; faixa alaranjada no meio do pronoto quase da mesma largura e toca a margem posterior; élitros, na metade anterior, com mancha preta, larga, sutural, fundida à mancha apical; limite entre a área amarelada e a preta do élitro, oblíquo em sentido descendente da sutura para a margem. (Galileo \& Martins, 2007: 71, fig. 5). Bolívia ............... E. piterpe Galileo \& Martins, 2007

28(25). Pronoto com abundante pubescência branca, exceto em área(s) no terço basal, castanho-avermelhada(s)

29

Pronoto com outro padrão de pubescência ............... 31

29(28). Élitros sem espículo no ângulo marginal .................... 30

Élitros com espículo no ângulo marginal. Fig. 6. Nicarágua ao Panamá ....... E. leuconoe (Bates, 1881)

30(29). Antenômero III preto, exceto anel basal amarelado; antenômero V e metade basal do VI, brancos; élitros com úmeros amarelados; pubescência fina e sedosa recobre inteiramente os élitros; metafêmures pretos. (Martins \& Galileo, 1989:83, fig. 10). Bolívia ............... .E. humeralis (Martins \& Galileo, 1989)

Antenômero III amarelado; antenômeros V e VI brancos; élitros sem áreas claras nos úmeros; pubescência branca, compacta em grandes áreas nos élitros; metafêmures amarelados. (Galileo \& Martins, 2005: 273, fig. 1). Costa Rica

E. cretaria (Galileo \& Martins, 2005)

31(28). Ápice dos élitros com espículo externo. (Galileo \& Martins, 2004: 251, fig. 3). Panamá

E. septuosa (Galileo \& Martins, 2004)

Ápice dos élitros arredondados 32

32(31). Antenômeros III a VII amarelados ou brancos. Fig. 3. Costa Rica ................................ E. esquinas sp. nov. Antenômeros III a VII com outro padrão de colorido

33(32). Antenômero III amarelado com o ápice preto, antenômero IV preto, $\mathrm{V}$ branco com anel basal preto, VI e VII inteiramente brancos, antenômeros IX-XI pretos. Fig. 1. Costa Rica ........... E. moysesi sp. nov.

Antenômeros com outro padrão de colorido .............. 34

34(33). Antenômeros III, IV e VI pretos, exceto anel basal amarelado; antenômero V inteiramente branco; úmeros amarelados. (Galileo \& Martins, 1999: 114, fig. 1). Paraguai, Argentina

E. atatinga (Galileo \& Martins, 1999)

Antenômero III inteiramente preto, metade apical do IV e V brancos; élitros inteiramente acastanhados sem áreas claras nos úmeros. Guiana Francesa, Brasil (Amazonas) E. cincticornis (Bates, 1866) 


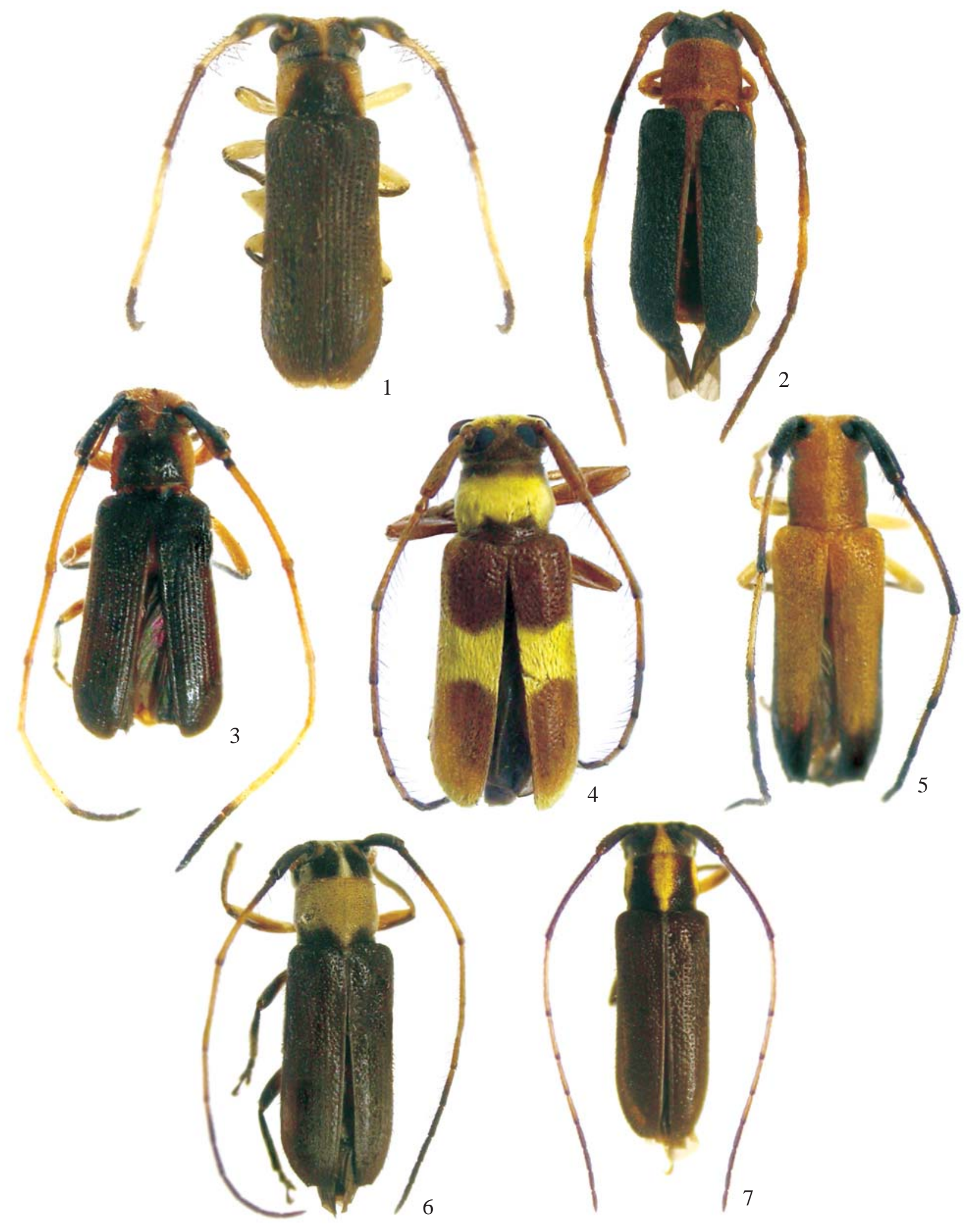

Figs. 1-7. 1, Eranina moysesi sp. nov., holótipo macho, comprimento $4,9 \mathrm{~mm} ; 2$, E. rondonia sp. nov., holótipo macho, comprimento $7,7 \mathrm{~mm}$; 3, E. esquinas sp. nov., holótipo macho, comprimento $6,2 \mathrm{~mm} ; 4$, E. hovorei sp. nov., holótipo macho, comprimento 5,8 mm; 5, E. fulveola (Bates, 1881), macho, 6,5 mm; 6, E. leuconoe (Bates, 1881), fêmea, 7,2 mm; 7, E. suavissima (Bates, 1881), fêmea, 6,4 mm. 


\section{Eraninella gen. nov.}

Espécie-tipo, Tyrinthia longiscapus Bates, 1881.

Fronte dos machos com pequeno tubérculo na região inferior (Martins \& Galileo, 1989: 74, fig. 1). Olhos inteiros, lobos oculares inferiores pouco mais longos que as genas; lobos oculares superiores pouco mais afastados entre si que a largura de um lobo. Mandíbulas com o ápice acuminado. Antenas com onze artículos. Escapo subcilíndrico, sem cicatriz, com densa pilosidade de pêlos longos entremeados por grande quantidade de pêlos curtos. Antenômero III levemente engrossado, mais longo do que o escapo e com o triplo do comprimento do IV; antenômero IV com o dobro do comprimento do V. Antenômeros III e IV com longos pêlos entremeados por pêlos curtos, densos. Antenômeros V a XI com comprimentos gradualmente decrescentes, a sua soma é menor que o comprimento do III. Protórax tão longo quanto largo, levemente abaulado nos lados. Pronoto sem tubérculos. Élitros ligeiramente expandidos para o lado externo na metade apical; sem carenas e sem franja de pêlos nas epipleuras; extremidades arredondadas. Mesofêmures sublineares. Metafêmures ligeiramente engrossados no meio. Garras tarsais com o dente interno tão longo quanto o externo.

Fêmea. Fronte sem tubérculo. Escapo, pedicelo e antenômero III com pêlos pretos ainda mais densos que os dos machos.

Discussão. Eraninella gen. nov. difere de Eranina pela presença de tubérculo na fronte dos machos; pela pubescência densa de pêlos longos e curtos no antenômero III; pelo comprimento do antenômero III com mais do que o dobro comprimento do IV e pelos élitros expandidos para o lado externo na metade apical.

Eraninella longiscapus (Bates, 1881), comb. nov.

Tyrinthia longiscapus Bates, 1881: 294.

Erana longiscapus; Martins \& Galileo, 1989: 74, figs. 1, 4. Eranina longiscapus; Monné, 2005: 466 (cat.).

Discussão. Eraninella longiscapus descrita originalmente do Rio de Janeiro, Rio de Janeiro, foi assinalada por Martins \& Galileo (1989) para Minas Gerais e Rio de Janeiro (Itatiaia) ao ser transferida para o gênero Erana.
Agradecimentos. A Larry G. Bezark, San Francisco, pelo envio de material e a Eleandro Moysés (MCNZ) pela execução das fotografias e tratamento das imagens.

\section{REFERÊNCIAS}

Bates, H. W. 1866. Contributions to an insect fauna of the Amazon Valley. Coleoptera: Longicornes. The Annals and Magazine of Natural History 17: 425-435.

Bates, H. W. 1874. Supplement to the longicorn Coleoptera of Chontales, Nicaragua. The Transactions of the Entomological Society of London, 1874: 219-235.

Bates, H. W. 1879-1885. Biologia Centrali-Americana, Insecta, Coleoptera. London, 5, $525 \mathrm{p}$.

Bates, H .W. 1881. Notes on longicorn Coleoptera. Revision of the aerénicides and amphionychides of tropical America. The Annals and Magazine of Natural History 8: 142-152, 196-204, 290306.

Bruch, C. 1911. Longicórnios argentinos nuevos o poco conocidos. II. Revista del Museo de La Plata 18: 164-178.

Fisher W. S. 1938. New neotropical Cerambycidae. II. Revista de Entomologia 8: 135-153.

Galileo, M. H. M. \& Martins, U. R. 1998. Notas e descrições em Lamiinae (Coleoptera, Cerambycidae) com garras tarsais apendiculadas ou bífidas e revisão do $1^{\circ}$. grupo de espécies do gênero Malacoscylus Thomson, 1868. Revista Brasileira de Entomologia 41: 249-256.

Galileo, M. H. M. \& Martins, U. R. 1999. Sobre alguns Lamiinae (Coleoptera, Cerambycidae) com garras tarsais apendiculadas e bífidas. Papéis Avulsos de Zoologia 41: 105-118.

Galileo, M. H. M. \& Martins, U. R. 2004. Novos Hemilophini (Coleoptera, Cerambycidae, Lamiinae) da Região Neotropical. Iheringia, Série Zoologia 94: 247-252.

Galileo, M. H. M. \& Martins, U. R. 2005. Novos táxons de Hemilophini (Coleoptera, Cerambycidae, Lamiinae) sem carenas nos élitros da região Neotropical. Revista Brasileira de Entomologia 49: 6368.

Galileo, M. H. M. \& Martins, U. R. 2007. Contribuição à taxonomia de três tribos de Lamiinae (Coleoptera, Cerambycidae). Iheringia, Série Zoologia 97: 67-72.

Martins, U. R. \& Galileo, M. H. M. 1989. Revisão das espécies sulamericanas do gênero Erana Bates, 1866 (Coleoptera, Cerambycidae, Lamiinae, Hemilophini). Iheringia, Série Zoologia: 71-83.

Martins, U. R. \& Galileo, M. H. M. 1993. Cerambycidae (Coleoptera) of the Canadian Museum of Nature, Ottawa. IV. Hemilophini (Lamiinae). Insecta Mundi 7: 169-173.

Monné, M. A. 2005. Catalogue of the Cerambycidae (Coleoptera) of the Neotropical Region. Part II. Subfamily Lamiinae. Zootaxa, 1023: $1-1024$. 